\title{
Examining the Influence of National Culture on Adoption and Use of Information and Communication Technology: A Study from Bangladesh's SME Perspective
}

\author{
Md. Shah Azam \\ Graduate School of Business, Curtin University \\ 78 Murray Street, Perth, WA 6000, Australia \\ Email: mdshah.azam@yahoo.com.au \\ Mohammed Quaddus \\ Graduate School of Business, Curtin University \\ 78 Murray Street, Perth, WA 6000, Australia \\ Email: mohammed.quaddus@gsb.curtin.edu.au
}

\begin{abstract}
Applying five cultural dimensions, power distance, uncertainty avoidance, in-group collectivism, Bengali value and ethical culture, along with the two fundamental antecedents of Technology Acceptance Model (perceived usefulness and perceived ease of use), this study examined the influence of culture on the adoption decision and use of ICT by SMEs in Bangladesh. This study used a mixed-method research approach, a combination of qualitative field study and quantitative survey. This paper reports the results of the quantitative questionnaire survey. Structural equation modelling was used to test collected data from 282 SMEs in Bangladesh. The results of this study reveal a significant association of in-group collectivism, ethical culture, Bengali value, perceived usefulness and perceived ease of use with SMEs' intention to use ICT as well as a strong and significant effect of intention on actual use of ICT by SMEs in Bangladesh.
\end{abstract}

Keywords: SME, Intention, ICT, National culture and use.

\section{Introduction}

Culture is a broad spectrum of behavioural study which has been illuminated differently in different literature. In general, culture can be defined as values, beliefs, norms, and behavioral patterns of a national group ${ }^{1}$. Reference 2 , treats culture as the collective programming of the mind that distinguishes the members of one group or category of people from another. Although the effects of culture on leadership and organisational processes as well as on the individual behaviour have successfully been looked into in many studies, ${ }^{4}$ its effects in ICT adoption research are inconclusive.

The role of culture is controversial in the use and adoption of information technology. Some researchers favour the thought that organisations adopt technology that is useful and provides them with some economic benefit where culture has no significant role in explaining organisational technology adoption behaviour. While other researchers hold an alternative view that culture plays an important role in determining not only whether organisations in a particular country adopt a certain technology but it also impacts the degree to which it is accepted and the ways it is used ${ }^{5}$.

Information and communication technology (ICT) has become an inevitable part of human life in almost every sphere of work around the world. The rapid growth of ICT usage has reshaped the ways of communication and also made changes in the strategies for organization both in the public and private sectors. Introduction of ICT, particularly the Internet, in the business sector not only involves changes to the systems, procedures, and processes of relevant services but also affects the way through which customers, suppliers, the regulatory 
bodies and other external parties deal with business organizations.

With its various advantages, such as lower cost, speed, accuracy, efficiency and opportunity to communicate regardless of time and place, information and communication technology has become the fastest diffused technological innovation to date.

Although the study of information and communication technology acceptance has received many researchers' interests in both developed and developing countries, ${ }^{6-19}$ in the last few decades, the amount of research looking at ICT from a developing country perspective is scarce. Recent Internet usage statistics suggest new opportunities for research pertaining to information technology adoption. These statistics may also attract researchers' attention towards developing and least developed countries along with the developed countries. Internet use in Bangladesh has been growing rapidly. The total Internet population of the country stands at 100,000 in the Year $2000^{20}$ and it reached 450,000 in the year $2007^{21,22}$, which indicates $450 \%$ rise in Internet population.

The rapidly increasing trend of ICT usage in business (particularly Internet use) provides a motivation for both large organizations and smaller ones in developing countries to adopt ICT.

Small and Medium Enterprises (SMEs) have played an important role in the economy. Although lagging behind their counterparts in developed countries, SMEs in developing countries contribute positively to the country's economy. SMEs account for about $45 \%$ of manufacturing in Bangladesh, about $80 \%$ of industrial employment, $90 \%$ of total industrial units, and $25 \%$ of the total labour force. Its total contribution to export earnings varies between $75 \%$ and $80 \%$ (Economic Census 2001-2003). The 2003 Private Sector Survey estimated that about six million micro, small, and medium enterprises defined as enterprises with fewer than 100 employees, contributed around $20-25 \%$ of Bangladeshi $\mathrm{GDP}^{23}$. The number of SMEs and its significant contribution to the national economy in terms of employment generation, GDP contribution and export earnings thus create a significant research opportunity to look at the adoption and diffusion of information and communication technology among SMEs in Bangladesh.

In the past, the adoption and diffusion phenomenon of ICT from an organizational perspective has been looked into mostly by anticipating the effects of innovation characteristics and the impacts of organizational, institutional and environmental forces. Although the cultural dimensions are important, they have not been studied widely in addressing the ICT adoption and diffusion. This study considers cultural dimensions as antecedents of ICT adoption and diffusion among the SMEs in Bangladesh, and this study applies a mixedmethod research approach which includes both qualitative field study and quantitative questionnaire survey.

\section{Theoretical Framework\& Hypotheses Development}

This research is, in general, an initiative of looking at the effects of different antecedents of ICT adoption and diffusion among SMEs in Bangladesh. Theory of Reasoned Action ${ }^{24}$, Rogers innovation diffusion theory ${ }^{25}$, Theory of Planned Behaviour ${ }^{26}$, and Technology Acceptance Model $^{27}$ have been analysed for the study.

According to Ref. 25, the decision process begins with knowledge of the existence of the innovation and matures through persuasion, decision and implementation stage. During the knowledge stage, a consumer is exposed to an innovation's existence and gains some understanding on how it functions, the persuasion stage refers to that period when a consumer forms either a favourable or an unfavourable attitude towards the innovation. Often, early adopters who are typically innovators themselves, or in some cases, exist as change agents, attempt to convince the general user population of the benefits of an innovation.

In the model of innovation diffusion, Ref. 28 indicates that the persuasion stage is very important to form a positive attitude (willingness or intention) to adopt the innovation. Rogers identifies all benefits and barriers as well as many other factors that affect this adoption as five attributes of innovation that are "the perceived characteristics of innovation" as perceived by an individual or organisation. These five attributes or characteristics of innovation consist of relative advantage, compatibility, complexity, trialability and observabiltiy.

The Theory of Reasoned Action ${ }^{24,31}$ is a well-researched theory for the study of behavioural intention by explaining causes of behavioural intent and illustrating the structures of relations. 
The Theory of Reasoned Action (TRA) has two unique factors, attitude toward the behaviour (ATT) and subjective norm ( $\mathrm{SN}$ ) that contribute to behavioural intention (BI), which finally explains the actual behaviour. The basic assumption underlying the theory of reasoned action is that humans are quite rational and make use of all available information, both personal and social, before they act. This theory has been reviewed and modified to explain behaviour comprehensively, one such modification, the Theory of Planned Behaviour (TPB) is a popular successive theory which explains the individuals' behaviour in a broader perspective than the TRA.

TPB was proposed by IcekAjzen ${ }^{26,30}$ which is an extension of theory of reasoned action ${ }^{29}$. TBP was developed to address the original model's limitations in dealing with behaviour over which people have incomplete volitional control ${ }^{26,30}$. Thus it overcomes the problematic predictive validity of the theory of reasoned action to explain the behaviour under study which is not under full volitional control. Ajzen ${ }^{26}$ made the extension by including one additional construct, namely perceived behavioural control, to predict behavioural intention and behaviour. Perceived behavioural control refers to "people's perception of ease or difficulty of performing the behaviour of interest" ${ }^{\prime 30(p .183)}$. A number of external factors (such as environmental, organisational etc.) can make a given behaviour easier or harder to perform.

The theory of planned behaviour (TPB) holds that human action is guided by three kinds of consideration which are: beliefs about the likely outcomes of the behaviour and the evaluations of these outcomes (behavioural beliefs), beliefs about the normative expectations of others and motivation to comply with these expectations (normative beliefs), and beliefs about the presence of factors that may facilitate or hinder performance of the behaviour and the perceived power of these factors (control beliefs). TPB also explains that certain factors or constructs known as control beliefs, may facilitate and impede peoples' behaviour, thus, can influence a persons' adoption intention or action (e.g., purchasing a product or service). ${ }^{31}$

The technology acceptance model (TAM) was developed by F. D. Davis ${ }^{27}$ to explain information technology (IT) usage behaviour. It is an adaptation of TRA and states that behavioural intention to use a technology is directly determined by two key beliefs: Perceived usefulness and perceived ease of use.
Perceived usefulness assesses the extrinsic characteristics of IT (i.e. task oriented outcomes) while perceived ease of use examines intrinsic characteristics of IT (e.g., ease of use, ease of learning, flexibility and clarity of interface). ${ }^{9}$

The earlier version of TAM included subjective norms along with perceived ease of use and perceived usefulness as antecedents of behavioral intention, and it was omitted from the model latter. Social influence has a strong effect in technology adoption in mandatory setting while it has different effects in voluntary setting and in the context of having experience. ${ }^{17}$ One key benefit of using TAM to understand system usage behaviour is that it provides a framework to examine the influence of external factors on system usage. ${ }^{32}$

Various external variables such as computer selfefficacy, social influence, experience, voluntariness, diversity of technology, trust, culture, and relevance, have been added in the context of TAM in different settings to get more insight into technology acceptance in previous initiatives. ${ }^{6,9,12,16-17,32-36}$

Although there is a lack of empirical studies reporting significant link between cultural dimension and different facets of IT use, ${ }^{37-44}$, Ref. 45 finds that the national culture and the ICT adoption rate of a country are closely related. They further report most of the Hofstede's dimensions ${ }^{3}$ are important in influencing adoption, and power distance and uncertainty avoidance dimensions seem to be most influential. Reference 5, supports this notion through their study of B2B ecommerce adoption in Taiwanese electronic industry. In addition to the two above mentioned cultural dimensions of power distance and uncertainty avoidance, this study anticipates the effects of three cultural dimensions, namely in-group collectivism, ethical culture, and Bengali value, on SMEs' adoption and use of ICT in Bangladesh. As a result, five dimensions of national culture are considered in this study:

- Power distance refers the degree to which members of a collective expect power to be distributed equally. ${ }^{4}$

- Uncertainty avoidance refers the extent to which a society, organisation, or group relies on social norm, rules and procedures to alleviate unpredictability of future events. ${ }^{4}$

- In-group collectivism refers the degree to which individuals express pride, loyalty and cohesiveness in their organisation and family. ${ }^{4}$ 
Ethical culture refers the extent to which a society, organisation, or group applies ethics and justice in their activities and discourages any form of corruption, nepotism or regionalism. Unlike uncertainty avoidance corruption, nepotism and regionalism have been reflected in almost everywhere in social, organisational and group activities in Bangladesh. These aspects of behavioural philosophies have been reflected frequently by many entrepreneurs while they were interviewed during field study, thus this aspect of culture has been coded as an added constructs for this study (Field study) . Bengali value is also another added cultural dimension which strongly guides and shapes human behaviour and communication. The field study revealed that people have feeling and respect to the language martyrs and a sentiment of upholding the Bengali language. It also found out people in different working environments feel comfortable with communication in Bengali language and love to maintain face to face communication and a close social bond. Unlike in-group collectivism stated in globe study ${ }^{4}$ these phenomena implies some other aspects of social collectivism, which is relevant to the Bengali culture in Bangladesh. Bengali value may be explained as the values that guide or motivate the individuals to maintain a very close social tie and become respectful to the Bengali language. This construct, although not been explained in previous cultural studies, is an important aspect of Bengali culture.

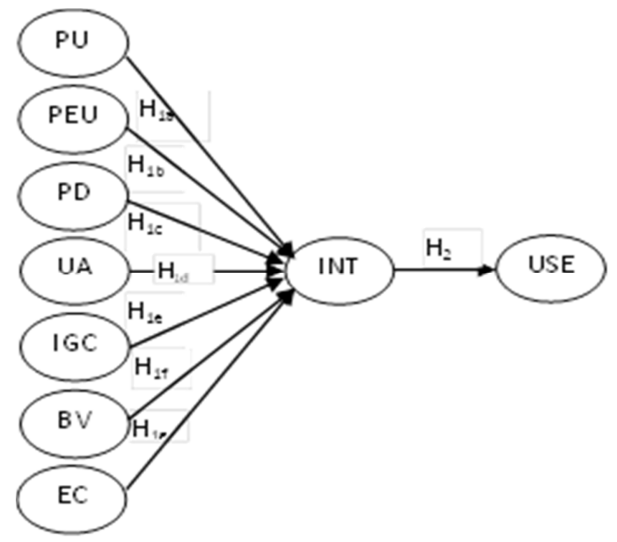

Note: $P U=$ perceived usefulness, $P E U=$ perceived ease of use, $P D=$ power distance, $U A=$ uncertainty avoidance, $I G C=$ in-group collectivism, $B V=$ Bengali value, $E C=$ ethical culture

Figure1: Final Research Model

\subsection{Hypotheses Development:}

Based on the above discussions the following hypotheses have been proposed (see Figure-1):

$\mathrm{H}_{1 \mathrm{a}}$ : Perceived usefulness has direct positive influence on SMEs' intention to use ICT.

$\mathrm{H}_{1 \mathrm{~b}}$ : Perceived ease of use has direct positive influence on SMEs' intention to use ICT.

$\mathrm{H}_{1 \mathrm{c}}$ : Power distance has direct negative influence on SMEs' intention to use ICT.

$\mathrm{H}_{1 \mathrm{~d}}$ : Uncertainty avoidance has direct negative influence on SMEs' intention to use ICT.

$\mathrm{H}_{1 \mathrm{e}}$ : In-group collectivism has direct negative influence on SMEs' intention to use ICT.

$\mathrm{H}_{1 \mathrm{f}}$ : Bengali value has direct negative influence on SMEs' intention to use ICT.

$\mathrm{H}_{1 \mathrm{~g}}$ : Ethical culture has direct negative influence on SMEs' intention to use ICT.

$\mathrm{H}_{2}$ : Intention has direct positive influence on SMEs' ICT use.

\section{Research Methodology and Findings}

This study applies a mixed method research approach. An in-depth field study was conducted to explore constructs and anticipate the structural links among them as well as fine-tune and contextualise the concepts developed from the literature. To test the model developed from the field study a questionnaire was designed for data collection. The measures of the questionnaire used to operationalise the constructs were adapted from relevant prior studies, taking into consideration of the findings of the field study and the targeted context. The developed questionnaire was further validated via pilot test. The final questionnaire was sent to owners or managers (decision maker) of SMEs or their delegated representatives in Bangladesh. With the assistance of a group of trained surveyors 282 survey responses were received. The collected survey data was analysed through PLS graph software. This paper reports the results of the questionnaire survey.

\subsection{Sample Selection}

The study investigates the opinions and perceptions of the owner or owner manager or manager (decision maker) or delegated representatives of SMEs located at or adjacent to Dhaka city. Dhaka has been selected as the sampling area considering the fact that high industry concentration is evident at or nearby Dhaka. The 
Internet penetration is also high at Dhaka which comprises around $80 \%$ of total country's Internet users.

\subsection{Demographic Information}

Table-1 presents the profile of survey respondents.

$56.7 \%$ of the respondents are from manufacturing industry and $43.3 \%$ from service industry. $14.22 \%$ surveyed have primary or secondary education, $64.5 \%$ of the respondents have graduate education, and $21.3 \%$ have post-graduation education. The study includes $60.3 \%$ individuals surveyed with an age below 35 years, $34.0 \% 35$ years to 44 years, while $5.7 \%$ respondents fall into the category of 45 years and above. $28.4 \%$ respondents have up to 20000Tk monthly income, $55.0 \%$ respondent earned Tk. 20000.00 to Tk 30000, while $16.7 \%$ respondents fall into the category of income more than 30000 Taka.

Table 1: Demographic profile

\begin{tabular}{llcc}
\hline & \multicolumn{1}{c}{ Description } & Frequency & \% \\
\hline Industry & Manufacturing & 160 & $56.7 \%$ \\
& Service & 122 & $43.3 \%$ \\
\hline Business & Small & 193 & $68.4 \%$ \\
Size & & & \\
& Medium & 89 & $31.6 \%$ \\
\hline Position & Manager ICT & 238 & $84.4 \%$ \\
& Manager General & 42 & $14.9 \%$ \\
& Others & 2 & $0.7 \%$ \\
\hline Age & $<35$ Years & 170 & $60.3 \%$ \\
& 35-44 Years & 96 & $34.0 \%$ \\
& 45-60 Years & 13 & $4.6 \%$ \\
& $\geq 60$ Years & 3 & $1.1 \%$ \\
\hline Education & Post graduate & 60 & $21.3 \%$ \\
& Graduate & 182 & $64.5 \%$ \\
& Literate up to & 40 & $14.22 \%$ \\
& Graduate & & \\
\hline Income & $<$ Tk. 20,000.00 & 80 & $28.4 \%$ \\
& Tk. 20,000 -Tk. & 155 & $55.0 \%$ \\
& 30,000 & & \\
& $>$ Tk. 30,000 & 47 & $16.7 \%$ \\
\hline ICT & Started ICT & 93 & $33.0 \%$ \\
Experience & before 2000 & & \\
& Started ICT since & 189 & $67.0 \%$ \\
& 2000 & & \\
\hline
\end{tabular}

Each of the respondents is using some sort of ICT. This survey confirms that the firm surveyed have Internet and ICT usage experience, $100 \%$ firms reported that they have online banking and some experience of online communication with main suppliers. $94 \%$ firms have cable broadband connectivity. $33.0 \%$ firms have a countable experience. They started ICT operations prior to 2000 while $67.0 \%$ started ICT operation after 2000 . $68.4 \%$ of the firms surveyed are small and $31.6 \%$ medium.

\subsection{Hypotheses Testing}

\section{Model Specification}

In the theoretical model, actual usage behaviour (B) has been modelled as a direct function of behavioural intention (BI). BI is in turn, a weighted function of perceived usefulness (U), perceived ease of use (E), power distance $(\mathrm{P})$, uncertainty avoidance $(\mathrm{A})$, in-group collectivism $(\mathrm{C})$, ethical culture $(\mathrm{H})$, Bengali value $(\mathrm{V})$ and error term (e).

$\mathrm{B}=\mathrm{w}_{1} \mathrm{BI}+\mathrm{e}$.

$\mathrm{BI}=\mathrm{w}_{2} \mathrm{U}+\mathrm{w}_{3} \mathrm{E}+\mathrm{w}_{4} \mathrm{P}+\mathrm{w}_{5} \mathrm{~A}+\mathrm{w}_{6} \mathrm{C}+\mathrm{w}_{7} \mathrm{H}+\mathrm{w}_{8} \mathrm{~V}+\mathrm{e} \ldots$ (2)

\section{Data Analysis and results}

The structural equation modelling is appropriate to analyse the data in accordance with the proposed conceptual framework. A growing number of researchers are adopting causal or structural equation modelling as it allows the analysis of complex networks of constructs, each construct typically measured by multiple variables. Understanding the nature of the study and its practical implications, the data gathered from the survey were analysed by partial least squares (PLS) based structural equation modeling. ${ }^{46}$

\section{Measurement model}

The measurement model was first assessed by a confirmatory factor analysis though PLS graph. The model, therefore, was assessed for evaluating the psychometric properties of the measurement model in terms of reliability, convergent validity, and discriminant validity. ${ }^{47}$ The reliability of the constructs was assessed by considering composite reliability. Construct reliability for all of the factors in the measurement model were above 0.70 , an acceptable threshold suggested by Ref. 48 .

Construct validity was evaluated by examining the factor loadings within the constructs as well as the correlation between the constructs. ${ }^{49}$ The factor loadings on all of the constructs were highly satisfactory in the expected direction with satisfactory critical ratio and level of significance (i.e. ranged between .568 to 
Table 2: Measurement Model-I

\begin{tabular}{|c|c|c|c|c|c|c|}
\hline Constructs & Items & Loadings & SE & T-Statistics & $\mathrm{CR}$ & AVE \\
\hline \multirow[t]{5}{*}{ Perceived Usefulness } & PPUU1 & 0.9615 & 0.0047 & 204.1158 & 0.97 & 0.866 \\
\hline & PPUU2 & 0.9637 & 0.005 & 191.6854 & & \\
\hline & PPUU3 & 0.9484 & 0.0076 & 124.9366 & & \\
\hline & PPUU4 & 0.9336 & 0.0085 & 109.4561 & & \\
\hline & PPUU5 & 0.8393 & 0.0198 & 42.395 & & \\
\hline \multirow[t]{5}{*}{ Perceived Ease of Use } & PPEU1 & 0.9502 & 0.0059 & 160.4382 & 0.979 & 0.94 \\
\hline & PPEU2 & 0.9285 & 0.0108 & 86.1774 & & \\
\hline & PPEU3 & 0.9624 & 0.0042 & 230.7146 & & \\
\hline & PPEU4 & 0.9506 & 0.0076 & 125.1943 & & \\
\hline & PPEU5 & 0.9621 & 0.0053 & 182.1819 & & \\
\hline \multirow[t]{4}{*}{ Intention } & INT1 & 0.8652 & 0.0141 & 61.1687 & 0.934 & 0.779 \\
\hline & INT2 & 0.8867 & 0.0139 & 63.7574 & & \\
\hline & INT3 & 0.863 & 0.0161 & 53.5029 & & \\
\hline & INT4 & 0.9152 & 0.0121 & 75.8613 & & \\
\hline \multirow[t]{4}{*}{ Use } & USE1 & 0.9232 & 0.0102 & 90.5594 & 0.937 & 0.79 \\
\hline & USE2 & 0.8531 & 0.0202 & 42.2879 & & \\
\hline & USE3 & 0.8892 & 0.0143 & 62.2267 & & \\
\hline & USE4 & 0.8875 & 0.0183 & 48.4449 & & \\
\hline \multirow[t]{3}{*}{ Power Distance } & POWDIS3 & 0.8929 & 0.0463 & 19.298 & 0.937 & 0.832 \\
\hline & POWDIS4 & 0.8992 & 0.0518 & 17.3493 & & \\
\hline & POWDIS6 & 0.9435 & 0.0187 & 50.5044 & & \\
\hline \multirow[t]{2}{*}{ Uncertainty Avoidance } & UNAVOID1 & 0.8637 & 0.2383 & 3.6243 & 0.929 & 0.868 \\
\hline & UNAVOID2 & 0.995 & 0.2496 & 3.987 & & \\
\hline \multirow[t]{2}{*}{ Ingroup Collectivism } & INGROUP2 & 0.5683 & 0.1591 & 3.572 & 0.776 & 0.651 \\
\hline & INGROUP3 & 0.989 & 0.0172 & 57.428 & & \\
\hline \multirow[t]{3}{*}{ Ethical Culture } & ETHICUL1 & 0.8199 & 0.0366 & 22.4075 & 0.916 & 0.786 \\
\hline & ETHICUL2 & 0.9235 & 0.013 & 71.2868 & & \\
\hline & ETHICUL3 & 0.9122 & 0.0111 & 82.3442 & & \\
\hline \multirow[t]{2}{*}{ Bengali Value } & BENVALU1 & 0.8518 & 0.0288 & 29.6193 & 0.885 & 0.794 \\
\hline & BENVALU2 & 0.9291 & 0.0138 & 67.5183 & & \\
\hline
\end{tabular}

Note: $A V E=$ Average variance extracted, $* * *=$ Significant at .001

.989), thus providing evidence of satisfactory item convergence on the intended constructs (see Table 2).

This study used the square root of the AVE and cross loading matrix to assess the discriminant validity as suggested by Ref. 50 and Ref. 46. According to Ref. 46, the model is assessed to have acceptable discriminant validity if the square-root of the AVE of a construct is larger than its correlation with other constructs. The results are detailed in Table 3 with the square roots of the AVEs shown in the main diagonal of the table. The off diagonal elements represent the correlations among the latent variables. Table 4 indicates that the discriminant validity of the latent variables was met, which means that all the latent variables are different from each other.

Discriminant validity of the measures has also been cross-checked through cross loading matrix. ${ }^{46}$ Results of the cross-loading analysis showed that all items 
loaded higher on the construct that they were measuring than they did on other constructs in the model. ${ }^{46}$ To save space, the cross-loading matrix is not presented in this paper.

\section{Structural model}

The structural model deals with testing the hypothesized relationships. Bootstrap method has been used to test the hypotheses. The results detailing the path coefficients and t-statistics are summarized in Table 4.

It is observed that among the primary hypotheses $\mathrm{H}_{1 \mathrm{a}}$, $\mathrm{H}_{1 \mathrm{~b}}, \mathrm{H}_{1 \mathrm{e}}, \mathrm{H}_{1 \mathrm{f}}, \mathrm{H}_{1 \mathrm{~g}}$ and $\mathrm{H}_{2}$ were supported (significant $\mathrm{t}$ values), while hypotheses $\mathrm{H}_{1 \mathrm{c}}$ and $\mathrm{H}_{1 \mathrm{~d}}$ were not supported (insignificant t-values). According to Ref. 51, the nomological validity or explanatory power of the proposed model can be assessed by observing the $\mathrm{R}^{2}$ values of the endogenous constructs. The model explains $58.6 \%$ of the variance $\left(\mathrm{R}^{2}\right)$ in intention to use ICT and $81.7 \%$ of the variance $\left(\mathrm{R}^{2}\right)$ in SMEs actual ICT usage behaviour. All $\mathrm{R}^{2}$ values exceeded the minimum required value of 0.10 as suggested by Ref. 52 (see Table 4).

The structural equation estimation shows that all constructs under the model are related in expected direction according to the proposed theoretical framework except power distance and in-group collectivism.

The study has shown that the proposed model can be used to explain intention to use as well as actual use of Information and Communication Technology by SMEs in the Bangladeshi setting.

The fundamental component of TAM, perceived ease of

Table 3: Measurement Model-II

\begin{tabular}{|c|c|c|c|c|c|c|c|c|c|c|}
\hline Factor & Items & PU & PEU & PD & UN & InGr & ECul & Bval & INT & USE \\
\hline $\mathrm{PU}$ & 5 & 0.931 & & & & & & & & \\
\hline PEU & 5 & 0.615 & 0.969 & & & & & & & \\
\hline PD & 3 & 0.157 & 0.133 & 0.912 & & & & & & \\
\hline UN & 2 & 0.004 & 0.141 & -0.059 & 0.932 & & & & & \\
\hline InGr & 2 & 0.065 & 0.041 & 0.049 & -0.315 & 0.867 & & & & \\
\hline ECul & 3 & -0.581 & -0.389 & -0.207 & -0.342 & 0.271 & 0.887 & & & \\
\hline BVal & 2 & -0.573 & -0.313 & 0.075 & -0.214 & 0.214 & 0.484 & 0.891 & & \\
\hline INT & 4 & 0.712 & 0.499 & 0.157 & -0.089 & 0.244 & -0.419 & -0.457 & 0.883 & \\
\hline USE & 4 & 0.731 & 0.523 & 0.214 & -0.181 & 0.253 & -0.413 & -0.378 & 0.804 & 0.889 \\
\hline
\end{tabular}

Note: $C R=$ Composite reliability, $P U=$ Perceived usefulness, $P E U=$ Perceived ease of $u$ use, $P D=$ Power distance,

$U A=$ Uncertainty avoidance, InGr=In-group collectivism, BVal=Bengali value, Ecul=Ethical Culture, Int=Behavioural intention, Use=Use of ICT

Table 4: Structural Model

\begin{tabular}{|c|c|c|c|c|}
\hline & Weight & SE & $t$-statistic & Comments \\
\hline $\mathrm{PU} \rightarrow \mathrm{INT}$ & 0.433 & 0.0719 & $6.0182 * *$ & Supported \\
\hline $\mathrm{PEU} \rightarrow \mathrm{INT}$ & 0.124 & 0.0566 & $2.1926^{*}$ & Supported \\
\hline $\mathrm{PD} \rightarrow \mathrm{INT}$ & 0.043 & 0.0362 & 1.1883 & Not Supported \\
\hline $\mathrm{UA} \rightarrow \mathrm{INT}$ & -0.11 & 0.0655 & 1.6803 & Not Supported \\
\hline $\mathrm{InGr} \rightarrow \mathrm{INT}$ & 0.248 & 0.038 & $6.5195^{* *}$ & Supported \\
\hline $\mathrm{BVal} \rightarrow \mathrm{INT}$ & -0.19 & 0.0473 & $4.015^{* *}$ & Supported \\
\hline $\mathrm{ECul} \longrightarrow \mathrm{INT}$ & -0.123 & 0.0518 & $2.3762 *$ & Supported \\
\hline $\mathrm{INT} \rightarrow \mathrm{USE}$ & 0.904 & 0.0095 & $95.1725 * *$ & Supported \\
\hline
\end{tabular}


use and perceived usefulness were found to have strong significant effects on behavioural intention. The result is complementary to some of the previous studies. ${ }^{53-56}$

The result is also complementary to the fundamental assumptions of TAM as supported by many previous studies. $^{6,8-9,16,27,34,57}$

As postulated the cultural dimensions have also significant influence in explaining SMEs' intention to use ICT and actual use behaviour. Among the five predicted cultural dimensions, uncertainty avoidance, Bengali value and ethical culture were found to have significant influence on intention, while power distance and in-group collectivism were found to have no significant influence on intention to use ICT among Bangladeshi SMEs.

Finally the results of this study confirms intention as a significant determinant of actual ICT use behaviour of SMEs in Bangladesh. This finding supports previous theories and empirical studies. ${ }^{6-8,16-17,22,24,29,58}$

\section{Discussions}

The structural equation model explains the joint effects of all constructs used in the model. The study depicts the magnitude and degree of the effects of the antecedent factors of ICT use among SMEs in Bangladesh. The study found that perceived usefulness, perceived ease of use, uncertainty avoidance, Bengali values, and ethical culture have significant influence on behavioural intention while power distance and in-group collectivism didn't produce significant effects. Thus hypotheses $\mathrm{H}_{1 \mathrm{a}}, \mathrm{H}_{1 \mathrm{~b}}, \mathrm{H}_{1 \mathrm{~d}}, \mathrm{H}_{1 \mathrm{e}}$, and $\mathrm{H}_{1 \mathrm{f}}$ were supported and $\mathrm{H}_{1 \mathrm{c}}$ and $\mathrm{H}_{1 \mathrm{~d}}$ were not supported. High power distance between top management and employees are evident in Bangladesh as in other developing countries. A discriminatory level of ICT resources and services usage is evident in Bangladeshi firms; not all levels of employees are given access or given the same level of access to the ICT. In addition, power distance is evident in both ICT adopting and non-adopting firms in Bangladesh. As a result, the hypothesised significant (negative) influence of power distance on intention to use ICT among SMEs in Bangladesh is not supported by the results of this study..

On the other hand the in-group collectivism, also hypothesised as negatively related to intention, was found to be positively related. This also happened as the in-group collectivism was measured through overall collectivism phenomena. The measurement items consider whether the managers encourage group loyalty and if the employees feel proud of the managers' individual accomplishment and vice versa. During the field study the in-group collectivism phenomena was reflected as a collective bargaining agent or various interest groups or subgroups within the organisation. Those phenomena are typically inhibiting ICT adoption and implementation, thus the construct was hypothesised to have a negative association with ICT adoption and use. The results of this study indicate that group performance or a sense of team work encourages and fosters ICT adoption and use among Bangladeshi SMEs.

The uncertainty avoidance dimension was found to have a non-significant association with intention to use ICT. It means that SMEs in Bangladesh are not well developed to face future uncertainties. They have not established a suitable environment (including proper structure and processes) required for successfully introducing ICT into the organization.

The Bengali value was found to have significant influence on intention to use ICT as the people of Bangladesh are very respectful to their language and language martyrs so they feel proud and comfortable in communicating in Bengali but not comfortable with the English language commonly used in ICT applications. Like the Bengali value, the ethical culture has characterised the culture of the country. Corruption, nepotism and regionalism have become common phenomena in Bangladesh. This cultural dimension also exhibited a negative and significant association with the intention to use ICT in this study. The results of this study indicate that any form of corruption, nepotism and regionalism inhibits adoption and use of ICT among Bangladeshi SMEs. Bangladesh is a country which received the top position in the world's most corrupt countries in three consecutive years (2004-2006). The introduction of ICT will help detect the corruption and unlawful works thus the government and concerned authorities will be able to easily take appropriate steps to combat the corruption and unjust activities and to establish economic and social justice.

Finally a strong and significant effect of behavioural intention on actual use behaviour is found. This result indicates that the positive and strong intention would foster the use of ICT in SMEs in Bangladesh. 


\section{Conclusions}

SMEs are considered an incubator of the national economy. The economic development of the country is largely dependent on the development of SMEs. Adoption and use of ICT can help develop SMEs by improving efficiency in their operations and by being more competitive in the global environment.

The government of Bangladesh is committed to establishing a computer driven society and utilising the potential of information and communication technology in the country's economic development. Thus ICT has been considered as a thrust sector of the country and numerous policies and priorities have been adapted to promote ICT adoption and use in the country. The government has also launched some motivational programmes to boost ICT usage in different sectors.

The present government of the country moves ahead with a slogan of establishing the Digital Bangladesh by 2021. To attain the target the government has also introduced some grants and subsidies and some other financial and infrastructural supports. This study explored a different aspect of ICT adoption and use among SMEs in Bangladesh. It is believed that a significant development will be evident if the government considers the cultural issues and motivates SMEs owners and other parties concerned to overcome the traditional hierarchical organisational systems where the authority and power is concentrated at the top of the hierarchy. In conjunction with the existing policies, supports, grants, subsidies and various motivational programmes, establishing a class-free network type of working environment may foster the rapid expansion of ICT adoption and use among SMEs in Bangladesh, which certainly will result in an improved organisational performance.

\section{Acknowledgement}

The authors are grateful to the participants of the $5^{\text {th }}$ Africa-Asia-Australasia Conference of the International Telecommunications Society, 13-16 November, 2011, Perth, Western Australia and CGSB Research Forum 2012, 21-22 March, Perth, Western Australia.

\section{References}

1. K. Leung, R. S. Bhagat, N. R. Buchan, M. Erez and C.B. Gibson, Culture and international business: Recent advances and their implications for future research,
Journal of International Business Studies 36(4) (2005) 357-378.

2. G. Hofstede, Culture's consequences comparing values, behaviours, institution, and organizations across the nations, 2nd ed. (Sage Publications, London, 2001).

3. G. Hofstede, Culture's consequences: International differences in work related values, abridged version (Sage Publications, London, 984).

4. R. J. House, P. J. Hanges, M. Javidan, P. W. Dorfman and V. Gupta, Culture, Leadership and Organizations: The GLOBE Study of 62 Societies (Sage Publications, Inc., California, 2004).

5. S.M.B. Thatcher, W. Foster and L. Zhu, B2B ecommerce adoption decisions in Taiwan: The interaction of cultural and other institutional factors, Electronic Commerce Research and Applications 5 (2006) 92-104.

6. S. Taylor and P. Todd, Assessing IT usage: The role of prior experience, MIS Quarterly 19 (4) (1995) 561-570.

7. S. Taylor and P. Todd, Understanding information technology usage: A test of competing models, Information Systems Research 6 (2) (1995) 144-176.

8. K. Mathieson, Predicting user intention: Comparing the technology acceptance model with the theory planned behavior, Information Systems Research 2(3) 1991) 173191.

9. F.D. Davis, R.P. Bagozzi and P.R. Warshaw, User acceptance of computer technology: A comparison of two theoretical models, Management Science 35(8) (1989) 982-1003.

10. F.D. Davis, User acceptance of information technology: system characteristics, user perceptions and behavioral impact, International Journal of Man-Machine Studies 38 (1993) 475-487.

11. G.C. Moore and I. Benbasat, Development of an instrument to measure perceptions of adopting an information technology innovation, Information Systems Research 2 (3) (1991) 192-222.

12. R. Agarwal and J. Prasad, Are individual differences germane to the acceptance of new information technologies? Decision Sciences 30 (2) (1999) 361-391.

13. T.S.H. Teo, M. Tan and W.K. Buk, (1998). A contingency model of internet adoption in Singapore, International Journal of Electronic Commerce 2(2) (1998) 89-102.

14. J.D. Kendall, L.L. Tung, K.H. Chua, C.H.D. Ng and S.M. Tan, (2001). Receptivity of Singapore's SME to electronic commerce adoption, Journal of Strategic Information Systems 10 (2001) 223-242.

15. M. Sathye and D. Beal, Adoption of electronic commerce by SMEs: Australian evidence, Journal of E-Business 1(1) (2001)1-11.

16. V. Venkatesh and F.D. Davis, A theoretical extension of the technology acceptance model: Four longitudinal field studies, Management Science 46 (2) (2000) 186-204.

17. V. Venkatesh and M.D. Morris, why don't men ever stop to ask for directions? Gender, social influences and their 
role in technology acceptance and usage behaviour, MIS Quarterly 24(1) (2000) 115-139.

18. V. Venkatesh, M.G. Morris, G.B. Davis and E.D. Davis, User acceptance of information technology: Towards a unified view, MIS Quarterly 27 (3) (2003) 425-478.

19. V. Venkatesh, S. A. Brown, L.M. Maruping and H. Bala, (2008). Predicting different conceptualizations of system use: The competing roles of behavioral intention, facilitating conditions, and behavioral expectation, $M I S$ Quarterly 32(3) (2008) 483-502.

20. M.S. Azam, Factors influencing the adoption of Internet: An inquiry into the perceptions of university academics in Bangladesh, in Proceedings of the 10th International Conference on Information Systems Analysis and Synthesis: ISAS 2004 and the International Conference on Cybernetics and Information Technologies, Systems and Applications (Florida, USA, 2004), pp. 138-143.

21. M.S. Azam and M. Quaddus, How organisational characteristics explain the adoption of e-commerce by the SMEs in Bangladesh? in Proceedings of the 20th Australasian Conference on Information Systems(ACIS) (Melbourne, Australia, 2009).

22. M.S. Azam and M. Quaddus, Internet usage behavior in Bangladesh: A test of theory of planned behaviour through structural equation modeling, in Proceedings of the Curtin International Business Conference (Mirri, Malaysia, 2009).

23. The New Nation, A national English daily, January 2, 2008. http://povertynewsblog.blogspot. com/2008/01/ bangladesh-bank-report-says-development.html, accessed 3 June 2008

24. M. Fishbein and I. Ajzen, Beliefs, Attitude, Intention, and Behavior: An Introduction to Theory and Research. (Addison-Wesley, Reading, MA, 1975).

25. E. Rogers, Diffusion of Innovations, 3rd ed. (Free Press, NY, 1983)

26. I. Ajzen, From Intentions to Actions: A Theory of Planned Behavior. in Action-control: From Cognition to Behavior, J. Kuhl and J. Beckman (eds.) (Springer, Heidelberg, 1985), pp.11-39.

27. F.D. Davis, Perceived usefulness, perceived ease of use, and user acceptance of information technology, MIS Quarterly 13 (3) (1989) 319-339.

28. E.M. Rogers, Diffusion of Innovation, 4th ed. (Free Press, New York, 1995).

29. I. Ajzen, and M. Fishbein, Understanding Attitudes and Predicting Social Behavior (Prentice-Hall, Englewood Cliffs, NJ, 1980).

30. I. Ajzen, The theory of planned behavior, Organizational Behavior and Human Decision Processes 50 (1991) 179211.

31. I. Ajzen and T.J. Madden, Prediction of goal-directed behavior: Attitudes, intentions, and perceived behavioral control, Journal of Experimental Social Psychology 22 (1986) 453-474.

32. W. Hong, J.Y.L. Thong, W.M. Wong and K.Y. Tam, 1999, Determinants of user acceptance of digital libraries: An empirical examination of individual differences and system characteristics, Journal of Management Information Systems 16 (2) (1999) 91-112.

33. H. Shih, Extended technology acceptance model of internet utilisation behaviour, Information \& Management 41 (2004) 719-729.

34. C. Yoon, The effects on national cultural values on consumer acceptance of e-commerce: Online shoppers in China, Information \& Management (2008) (Accepted for publication on 1/6/2009).

35. V. Venkatesh and F.D. Davis, A model of the antecedents of perceived ease of use: development and test, Decision Sciences 27 (1996) 451-481.

36. Y. Wang, Y. Wang, H. Lin and T. Tang, Determinants of user acceptance of internet banking: An empirical study, International Journal of Service Industry Management 14 (5) (2003) 501-519.

37. D.S. Bertolotti, Culture and Technology (Bowling Green State University Press, Bowling Green, OH, 1984).

38. J.M. Burn, (1995). The new cultural revolution: The impact of EDI on Asia. Journal of Global Information Management 3(4) (1995) 6-23.

39. M. Erez and P.C. Early, Culture, self-identity and work (Oxford University Press, New York, NY, 1993).

40. D. Gefen and D.W. Straub, (1997). Gender differences in the perceptions and use of e-mail: An extension of technology acceptance model, MIS Quarterly 21(4) (1997) 389-400.

41. C. Hill, K. Loch, D.W. Straub and K. El-Sheshai, A qualitative assessment of Arab culture and information technology transfer, Journal of Global Information Management 6 (3) (1998) 29-38.

42. T.H. Ho, K.S. Raman and R.T. Watson, Group decision support systems: The cultural factors, in Proceedings of the 10th Annual International Conference on Information Systems (Boston, MA, 1989), pp. 119-129.

43. D.W. Straub, The effects of culture on IT diffusion: Email and fax in Japan and the US, Information Systems Research 5(1) (1994) 23-47.

44. R. Harris and R. Davison, Anxiety and involvement: Cultural dimensions of attitudes toward computers in developing societies, Journal of Global Information Management 7(1) (1999) 26-38.

45. A.A.A. Erumban and S. B. de Jong, Cross country differences in ICT adoption: A consequence of culture? Journal of world Business 41(2006) 302-314.

46. D. Barclay, C. Higgins and R. Thompson, The partial least squares (PLS) approach to causal modeling: Personal computer adoption and use as an illustration, Technology Studies 2 (2) (1995) 285-309.

47. C. Fornell and D. Larcker, Evaluating structural equation models with unobservable variables and measurement error, Journal of Marketing Research 18 (1981) 39-50.

48. J. C. Nunnally and I. H. Bernstein, Psychometric Theory (McGraw-Hill, New York, 1994).

49. J. C. Anderson and D.W. Gerbing, Structural equation modeling in practice: A review and recommended two- 
step approach, Psychological Bulletin 103(3) (1988) 411423.

50. M. Igbaria, T. Guimaraes and G.B. Davis, Testing the determinants of micro computer usage via structural equation model, Journal of Management Information Systems 11(4) (1995) 87-114.

51. P.I. Santosa, K.K. Wei, and H.C. Chan, User involvement and user satisfaction with information-seeking activity, European Journal of Information Systems 14 (2005) 361370.

52. R.F. Falk and N.B. Miller, A Primer for Soft Modelling (University of Akron Press, Akron, 1992).

53. B. Szajna, Empirical evaluation of the revised technology acceptance model, Management Science 42(1) (1996) $85-92$.

54. G.H. Subramanian, A replication of perceived usefulness and perceived ease of use measurement, Decision Science 25(5-6) (1994) 863-874.

55. P. Chau and $\mathrm{P}$. $\mathrm{Hu}$, Investigating healthcare professionals' decisions to accept telemedicine technology: An empirical test of competing theories, Information and Management 39(4) (2002) 699-719.

56. P.Y.K Chau, An empirical assessment of a modified technology acceptance model, Journal of Management Information Systems 13(2) (1996) 185-204.

57. J. Lu, C.S. Yu, C. Liu and J.E. Yao, Technology acceptance model for wireless Internet, Internet Research 13(3) (2003) 206-222.

58. M.K. Chang, Predicting unethical behaviour: A comparison of the theory reasoned action and the theory of planned behaviour, Journal of Business Ethics 17 (1998) 1825-1834. 